\title{
OS VALORES SOCIAIS NA RECUPERAÇÃO ECONÔMICA DO JAPÃO APÓS A SEGUNDA GUERRA MUNDIAL
}

Elvino José Barbosa*

RESUMO: É muito importante tentarmos entender o milagre japonês através de outros valores além daqueles apontados, valorizados e considerados dentro do âmbito da racionalidade do indivíduo, apontados pela ciência Econômica. Esse é o nosso objetivo nesse trabalho, onde chamaremos a atenção para os valores sociais, importantes fatores na recuperação econômica do Japão após a Segunda Guerra Mundial.

ABSTRACT: It is very important to try to understand the Japanese miracle investigating the economic process as a whole trying to find out new values outside the rationality behavior proposed by the Economy Theory. It is our purpose in this work to throw more light on the subject drawing the reader's attention for the social values that were so important in order to recover Japanese Economy after Second World War.

PALAVRAS-CHAVE: Giri, Ninjô, Wa, Governo, Empresa

KEYWORDS: Giri, Ninjô, Wa, Government, Enterprise

\section{Introdução}

Muito se tem dito a respeito do rápido desenvolvimento econômico verificado no Japão após a Segunda Guerra Mundial, mas poucos têm sido os estudos que procuraram

* Graduado em Economia (Faculdade de Economia e Administração da Universidade de São Paulo - FEAUSP), Administração Pública (Escola de Administração de Empresas de São Paulo da Fundação Getúlio Vargas - EAESP-FGV), aluno do curso de Língua e Literatura Japonesa (FFLCH-SP), Mestre e Doutorando em Economia de Empresas (EAESP-FGV), Pesquisador do Centro de Estudos Japoneses da Universidade de São Paulo (CEJ-USP). 
fazer uma análise mais abrangente do processo, buscando causas mais amplas através da interface de diferentes disciplinas, como a sociologia, a economia, a ciência política etc. A grande maioria tem ficado presa apenas a uma análise de caráter conjuntural da economia e de onde derivam suas conclusões e deduções.

Obviamente, são trabalhos de grande valor e de grande importậncia, na difícil tarefa de conceituar e precisar melhor o milagre japonês após a Segunda Guerra Mundial. Não obstante, estamos ainda diante de terreno pouco conhecido quando estudamos o Japão em seus mais diferentes enfoques. Trata-se, entretanto, de missão muito difícil e complexa explicar as transformaçōes econômicas pelas quais passou o Japão levando em conta o seu aspecto social.

Diante dessa constatação, obtida através da leitura de diferentes estudiosos, principalmente economistas e sociólogos, decidimos estudar três importantes elementos culturais presentes na sociedade japonesa desde há muito tempo, remontando mesmo à sua formação histórica e que serviram de elementos aglutinadores importantes no processo de reconstrução do país a partir das cinzas. São eles: as concepções de giri ("dever"), ninjô ("sensibilidade humana") e wa ("harmonia") que, justamente por serem culturais, subjetivos, permaneceram incólumes às influências externas das Forças de Ocupação a partir de 1945. O mesmo não se podendo dizer com relação às organizações políticas e econômicas, que passaram por grandes transformações.

A permanência desses elementos culturais permitiu, por exemplo, a reestruturação das instituições japonesas após a Segunda Guerra - não obstante a insistência e exigência das Forças de Ocupação para que se efetuassem mudanças profundas - em moldes onde ainda se faziam presentes valores tradicionais da cultura, presentes desde há muito tempo.

As mudanças, de maneira geral, agradavam os interesses externos, mas o comportamento dos funcionários japoneses nas novas organizações, paulatinamente, acabava retomando as antigas formas de concepção e de funcionamento; retomavam, por exemplo, critérios organizacionais secularmente arraigados na estrutura organizacional das instituições, fazendo valer critérios e valores como a disciplina, a ordem, a obediência, a harmonia, o dever a noção de grupo etc., todos, insistimos, existentes já anteriormente à deflagração da guerra.

Esse contraste entre exterior e interior, entre ambiente interno e externo, entre a ação que praticavam e o sentimento que experimentavam ao praticá-lo, acabava gerando um sentimento de insatisfação no indivíduo japonês, obrigado a seguir uma orientação e a desenvolver atividades e comportamentos alheios ao seu repertório, o que propiciou o surgimento da expressão conhecida em língua japonesa como menjû fukuhai, que tem o sentido de "seguir as ordens de um superior na sua presença mas remoendo-se por dentro em sua barriga", isto é, pratica-se o ato de obediência, mas conservando-se no interior do indivíduo, o sentimento de contrariedade.

É preciso observar que a Constituição de 1947, a primeira do pós-guerra, foi imposta ao Japão e, devido ao seu objetivo, estava predominantemente impregnada de caráter político-econômico, pouco ou quase nada fazendo no sentido de romper ou modificar a formação do caráter do povo japonês, o que levou alguns autores a se referirem ao Estado Japonês com expressões e termos do tipo web society, Japan, Inc. society of web connections, bureaucratic industrial complex e outros. 
O objetivo deste trabalho não é, obviamente, produzir resultados fechados e inquestionáveis no estabelecimento de novos conceitos e perspectivas que possibilitem uma melhor compreensão do caso Japão, mas, já nos damos, de certa forma, por satisfeitos dado que pelo menos estamos levantando um debate sobre um assunto ainda não totalmente esclarecido e que, sem dúvida, merece a nossa atenção até mesmo para uma maior reflexão e comparação com outras sociedades em determinados momentos de suas histórias.

\section{Giri Ninjô e Wa: O Difícil Problema da Conceituação}

Devido a fatores que fogem ao âmbito deste trabalho, a sociedade japonesa desenvolveu um sistema baseado em normas de comportamento e de pensamento diferentes, por exemplo, dos conceitos e práticas ocidentais do que é "certo" e do que é "errado" que têm por base um corpo de leis. Assim, no caso japonês, o sistema de norma e regras estabelecidas pela sociedade a partir de seu funcionamento, seguindo uma orientação de natureza não legal antecedeu, desde há muito tempo, todas as orientações do Estado em sua história. A tradição é um elemento que não é descartado tão rapidamente.

Esse mecanismo apresenta profundas raízes e ainda hoje continua muito vivo, funcionando lado a lado com os mecanismos mais definidos e mais sofisticados, segundo a visão ocidental, de organização patrocinados pelo Estado. Esse fato também em muito contribuiu para que o Japão, a partir de seu processo de democratização - desencadeado a partir de 1945 com as Forças de Ocupação - e de abertura para o Ocidente - a partir de 1960 -, fosse melhor entendido pelo exterior e para que também seu povo melhor entendesse e melhor digerisse uma rápida e inusitada avalanche de informações cuja finalidade específica era a de reconstruir o país o mais rápido possível. Portanto diríamos que, a despeito do período de agruras e de misérias que se abateu sobre a população japonesa no pós-guerra - ou seja, efeitos de curtíssimo prazo, usando uma linguagem mais econômica -, a influência externa afetou apenas o exterior dos indivíduos mas conservando intactos os seus valores sociais e culturais mais caros.

Nesse sentido, muitas das tentativas de transformações impostas pela Ocupação não frutificaram, ou se preferirmos novamente uma abordagem econômica, os efeitos de médio e longo prazos vieram, ao contrário, corroborar a permanência dos valores sociais (giri, ninjô e wa), fazendo com que as vantagens (os dividendos) fossem mais do que compensadores.

Essa combinação envolvendo passado e presente, o arcaico e o moderno, acabaram criando um solo fértil para a permanência, desenvolvimento e mesmo de sofisticação dos valores sociais remanescentes dos períodos anteriores à Segunda Guerra Mundial.

Os valores sociais permitiram ao Estado passar de uma orientação de "Estado militarmente poderoso" para "Estado economicamente competitivo" Seus principais pilares eram: estabilidade política, ordem social, direcionamento das empresas para seguirem sua política industrial e a orientação de se ter uma força de trabalho estável, condição fundamental para se desenvolver economicamente. 


\subsection{O Giri}

O conjunto de normas e regras sociais baseados na tradição e no desenvolvimento do estado social é conhecido por giri. O giri envolve regras de conduta, não pressupõe a existência de qualquer relação clara ou definida das noções de direito e de dever entre as partes envolvidas, que compreendem indivíduos e grupos.

A palavra giri é de difícil definição, mesmo entre os japoneses, porque ela evoca muitas idéias, que também são de difíceis interpretações e explicações, segundo termos e conceitos ocidentais.

Por estarmos trilhando por terra incógnita, tentaremos determinar algumas de suas características para que possa haver melhor compreensão.

a) Giri é o dever que um indivíduo tem para com outro indivíduo ou para com o grupo (grupo ao qual ele pertence ou qualquer outro grupo externo); devido a uma relação - material ou não -, ocorrida entre as partes envolvidas, estabelece-se um "laço", uma ligação, um envolvimento entre ambos. Esse dever ou obrigação varia muito de situação para situação e de intensidade, de acordo com a hierarquia das pessoas envolvidas na relação. Assim sendo, há, por exemplo, o giri de uma criança para com seus pais, o giri entre amigos, o giri entre aluno e professor etc.

b) A pessoa para a qual se deve um giri não tem o direito, em nenhum momento, de cobrá-lo. Deve esperar pacientemente pelo cumprimento voluntário da ação que envolve a realização do giri. O não cumprimento a gosto do giri acaba gerando uma situação de desconforto e se aproximando do conceito ocidental de deslealdade. Ainda assim, não se pode cobrá-lo, como se cobra a honestidade em oposição à desonestidade em termos ocidentais; a cobrança levaria a uma quebra , a uma violação do giri. Além disso, é muito comum que ambas as partes -beneficiador e beneficiado - estejam mutuamente envolvidos por giri.

c) As relações por giri são perpétuas. Não são extintas mesmo quando realizadas, isto é, não se esgotam quando da realização, da sua execução, o que é um traço que reforça bem a idéia de estarmos diante de conceitos e idéias completamente diferentes do que temos em mente no Ocidente, onde uma ação pode perfeitamente compensar uma outra, o que também pode ser colocado em termos econômico-contábeis: um débito pode ser saldado por um crédito de igual valor ou um passivo pode ser perfeitamente zerado com um ativo de igual montante.

As relações por giri transcendem no tempo e não se conhece limitações de amplitude: estão continuamente conferindo substrato para o estabelecimento e nascimento de uma constelação de "deveres" e "obrigaçōes" acrescidas ao fato de serem permanentes.

d) Essas relações têm seus substratos no sentimento, na emoção por afeição. Não se pode, em momento algum, interpretar o estabelecimento dessas relações segundo o mecanismo econômico-contábil referido acima; não se busca, por exemplo, colocar alguém numa condição de dependência para se extrair daí lucros, proveito ou benefício próprio.

Pelo menos do ponto de vista da aparência, o indivíduo japonês procura desenvolver um comportamento isento de intenções; age por sentimentos de afeição 
estabelecidos intra-grupo associados ao sentimento do dever, da obrigação. Depois de consolidada, o mais sólida possível a sua base grupal, parte-se para o relacionamento intergrupos.

e) as relações por giri não são impostas e nem cobradas por interesse ou por relações públicas; não são fruto de um contrato, antes são estabelecidas e sancionadas através do sentimento de honra. Quem falhar nas relações de giri, portanto, é seriamente desonrado perante o seu grupo.

Nesse aspecto, destaca-se talvez o maior traço da cultura japonesa: a questão da honra como fiel da balança diante das mais diversas situaçōes em que toma parte o indivíduo no seu relacionamento com os demais. A todo instante o que é fundamental é a preservação e manutenção da honra ainda que muitas vezes isso implique em desvantagens (prejuizos) próprias em favor (benefício) do grupo, por exemplo. Sendo honrado, não se tem vergonha, um outro conceito que rivaliza, em importância, com a honra.

Esses sentimentos de vergonha e de desonra, na origem, são muito fortes e decisivos em "coibir", em "deter", em "controlar" e, em última instância, sinalizar o indivíduo, levando-o a responder favoravelmente para o bom e adequado cumprimento das suas obrigações de giri.

No caso da sociedade japonesa, onde temos uma situação completamente oposta, isto é, uma sociedade baseada na noção da honra e da vergonha, conforme visto, o indivíduo está continuamente atento e preocupado com a presença, com as atitudes e, em maior grau, com as possíveis sanções dos outros, mesmo nas situações mais triviais da vida diária.

Ruth Benedict conclui que é justamente por causa dessas sanções psicológicas, provenientes da noção de se estar sendo sempre observado, que as regras de giri são tão estritamente observadas no caso da sociedade japonesa.

\section{$2.2 O$ Ninjô}

O sentimento de afeição associado ao sentimento de dever, de obrigação, referido acima, corresponde ao conceito de ninjô, outro dificílimo termo de se definir. Talvez a melhor aproximação seria dizer que é o termo correspondente ao sentimento natural de afeição relacionado à sensibilidade humana.

Os dois sentimentos, giri e ninjô, estão intimamente relacionados levando muitos estudiosos a estudá-los englobadamente segundo o termo composto giri-ninjô.

Caso uma pessoa aja em interesse próprio, ela é considerada uma pessoa que não tem consciência de seu ninjô. Se no caso do giri a sua não observação leva a uma noção de deslealdade, no caso da falta de realização do ninjô o indivíduo é considerado fora dos padrões esperados e é, de certa forma, colocado à margem do devido e aceitável comportamento estabelecido socialmente.

\section{$2.30 \mathrm{Wa}$}

Esse talvez tenha sido o conceito mais explorado pelo Estado Japonês após a Segunda Guerra Mundial, uma vez adotada a política de se reconstruir o país a partir 
das cinzas. O conceito de wa corresponde ao de "harmonia", de fundamental importância para, também, aproximar as partes envolvidas (indivíduos e grupos) derivando dessa associação, uma aparente comunhão de interesses. A partir do wa é possível chegar-se a uma posição em favor do grupo, visando o coletivo, ainda que isso resulte em certas perdas individuais.

Ao invés do conflito aberto entre as partes, entre os grupos de interesses contraditórios, uma vez sob uma mesma organização, há um grande esforço para que se chegue a um consenso, o que mostra a importância do wa e da noção de grupo.

No caso específico do pós Segunda Guerra, os efeitos desse conceito podem ser sentidos nos seguintes aspectos:

atenuou as disputas entre os diversos setores e permitiu às partes envolvidas (notadamente o governo e o setor privado) a chegarem ao consenso de que o prioritário, no curto prazo, era a recuperação econômica;

uma vez na empresa, trabalhadores e patrões, após um rápido período de agitações trabalhistas (logo após a Guerra) perceberam que seria praticamente impossível reconstruir o país se se arraigasse o sistema de disputas entre empresas e trabalhadores tão rapidamente trazidas pelo vendaval da Ocupação, importado do Ocidente. No Japão, ainda hoje, não vingaram os padrões ocidentais de organização sindical de âmbito nacional; o que permaneceu foi o sistema de sindicatos em bases empresariais: cada empresa é vista como uma organização (um grupo) à parte havendo forte vinculação entre o indivíduo e a empresa, com profundos laços de fidelidade e obediência recíproca;

a permanência do conceito de wa permitiu ao país não perder, portanto, a noção da nação como uma grande família, tão bem trabalhada e incentivada em períodos anteriores, ainda que, após a Guerra, tenha adquirido conotação menos política que antes; observou-se uma grande proliferação de associações envolvendo trabalhadores, empresas, setores sociais, políticos e profissionais liberais; essas organizações contavam também com a participação de membros do governo. A idéia era colocar sociedade civil, políticos e governo diante de interesses comuns;

assim, no pós-guerra, o indivíduo reproduz na empresa os conceitos que até então eram aplicados a nível de grupos sociais de caráter informal.

Para Chalmers Jonshon (1975), harmonia ( $w a$ ) foi o amálgama que manteve os setores econômicos, a mão-de-obra, políticos e o governo em perfeita associação.

Além disso, até hoje, as empresas japonesas estão organizadas de tal forma a pertencerem a uma única associação, cada uma associada ao seu setor industrial evitandose, assim, o problema de se ter que prestar obediência e/ou se ver dividida entre dois polos de interesses. Pertencendo a uma única organização (grupo) fica resolvida a questão de se ter que prestar lealdade ( $g$ iri) a dois grupos, o que seria ainda mais difícil.

Essa questão do giri no nível empresarial pode ser constatada na relação entre uma empresa fornecedora e uma empresa cliente: uma vez estabelecida a relação fornecedor-cliente dificilmente ela é rompida e quando uma das partes estiver em dificuldades a outra sempre procura cooperar no sentido de prestar auxílio. Isso acabou gerando as grandes redes de distribuição ( $k a i)$ e do fenômeno do keiretsu (conglomerados 
econômicos) do Japão após 1945 , onde a fidelidade empresarial desfruta de grande prestígio.

Dentro da empresa o processo de obtenção e formação do consenso ocorria segundo o processo do ringi seido: cada nova proposta relacionada à empresa era freqüentemente proveniente dos escalōes mais baixos, até mesmo das linhas de produção; essas propostas passavam por todos os escalōes da empresa ao longo da hierarquia, sendo colhidas aprovações, reprovações ou revisões até chegar ao presidente da empresa. Uma vez aceita a proposta, havia um consenso organizacional, passando-se imediatamente a sua execução através da devida preparação (nemawashi) da empresa para incorporar a mudança, não se atribuindo menções individuais; a idéia passava a ser de todos.

A sociedade japonesa do pós-guerra ainda mantinha assegurada, na sua constituição, a participação dos diversos grupos, representados pela família, pela escola e pela empresa. Esse processo de interação pode ser considerado uma decorrência da estruturação social japonesa onde, desde muito tempo atrás, o indivíduo estava primeiramente ligado a sua família (ie) sem perder seus vínculos com o seu grupo comunitário (sua aldeia, ou vilarejo (mura)), e as normas e condutas sociais continuavam reforçando e incentivando a harmonia através da cooperação, pelo menos uma cooperação suficiente para se traçar um consenso. Havia a formação de uma relação emocional de mútua dependência variando em grau e escala; sob esse traço, um serviço prestado em condições sociais, políticas e econômicas normais se constituía em vínculo indicador de reciprocidade e de favor em tempos de crise e de dificuldades, o que facilitava o funcionamento molecular e orgânico da empresa japonesa, diferentemente do modelo ocidental, em que prevalecia o modelo atômico e inorgânico. Era inconcebível, por exemplo, uma empresa falir por agir isoladamente sem estar associada de algum modo a um banco, a uma trading, a um partido político, ou a alguma organização do setor privado e/ou governamental.

Todas essas características serviram para neutralizar e atenuar os conflitos de interesses decorrentes de um funcionamento normal (segundo padrões ocidentais) da sociedade. Essa contenção de forças antagônicas, e que poderiam entrar em choque com as orientações econômicas e políticas do governo, foram estendidas às relações de trabalho, ao gerenciamento das empresas, ao relacionamento entre governo e indústria etc., tornando-as muito mais cooperativas e mutualmente benéficas.

Como se pode ver, os ângulos de análises são muito amplos e esperamos, conforme já dito, que este trabalho sirva de incentivo a outras investigações, dando margem a discussões de âmbito interdisciplinar maior, sem se ficar preso a disciplinas isoladas como a economia ou a sociologia.

\section{Os Valores Sociais e a Recuperação Econômica}

Ao se estudar mais detalhadamente o sucesso econômico do Japão no Pós-Guerra, deparamos, desde início, com um fato deveras interessante e sempre presente na história da sociedade japonesa desde tempos remotos e que, conforme veremos, também desempenhou papel decisivo na recuperação do pós-Guerra. Trata-se da capacidade e/ 
ou poder de adaptação, preservação e transformação dos seculares valores culturais presentes na sociedade japonesa.

Como resultado das leituras de vários autores que se empenharam no estudo do milagre econômico japonês, desde início, algo muito forte se nos afigura: o fato de que para entender o mistério do sucesso econômico japonês faz-se necessário lançar mão de um enfoque interdisciplinar envolvendo a Sociologia, a Política, a Economia, a Cultura Organizacional etc. presentes no caso japonês e, fundamentalmente, os vários graus de relação entre essas disciplinas, pois só assim será possível entender melhor o processo.

Trata-se então, de se procurar ver o processo pela base e pelas suas relações e não pelo topo como, infelizmente, percebemos nos trabalhos de alguns autores.

\section{Conclusões e Fatos Relevantes}

1) No estudo do processo de recuperação econômica do Japão constatamos a presença de uma grande malha institucional operando segundo duas componentes: a via formal e direta (patrocinada pelo Estado, pelos ministérios, pelas associações empresariais, pelas empresas etc.) e a via informal e indireta (dada pelo inconsciente social, como normas de comportamento, de organização, de reivindicação de direitos etc.);

A unidade celular social, no caso japonês, é o grupo e não o indivíduo;

Há um código cultural e hierárquico herdado que organiza e predispõe a sociedade, facilitando a invocação de posturas e condutas condizentes e favoráveis à formação e obtenção de consenso diante de todas as situações que envolvem decisões de grande importância. Nesse sentido, ganha real importância o conceito de wa, notadamente entre empresas e entre essas e seus funcionários;

Há um sistema educacional extremamente orientado, de forma que o Estado atraía para si os mais talentosos e mais brilhantes alunos após a conclusão de um curso superior através de acirrado processo de seleção. Isso possibilita ao governo contar com a melhor equipe possível de burocratas em seus ministérios;

O sistema, por estar baseado em valores culturais e sociais, além dos valores econômicos e políticos, permite ao Estado treinar e formar uma elite burocrática especializada para a condução do país. Essa constelação de valores permitiu ao Estado minimizar conflitos de interesses e conferir flexibilidade, levando o sistema a funcionar como um eliminador ou minimizador de divergências, possibilitando maior coesão social para enfrentar os problemas de âmbito nacional;

Os valores sociais herdados permitiu uma forte interação entre a máquina governamental, os ministérios - notadamente os ministérios da área econômica: MICI (Ministério da Indústria e Comércio Internacional) e MF (Ministério das Finanças) e o Partido Democrático Liberal (PDL) - principal partido político do pós-Guerra na formação do consenso em que se procurava ouvir todas as instâncias envolvidas (processo conhecido por iken o matomeru (iken: opinião, ponto de vista, idéia, sugestão; matomeru: resolver (uma disputa, por exemplo), colocar um assunto sob acordo, concluir uma negociação); 
A presença de uma elite burocrática forte e de orientação pró-industrialização permitiu, desde cedo, impor-se uma orientação industrial constante, sem vacilações, processo esse facilitado pela existência de valores sociais, como o giri, o wa e o ninjô;

Essa elite compreendia, principalmente, a elite da administração central do governo, compreendendo posições acima dos diretores de departamentos, graduados, principalmente, na Universidade de Tóquio. Essa elite burocrática era forte pois reunia a elite do poder e compreendia, além de burocratas de carreira ligados ao serviço público, importantes líderes políticos;

"A elite do Japão não deve ser vista simplesmente como uma configuração de poder político e econômico [...] mas, antes, como uma parte orgânica da sociedade japonesa" (Hellmann, D. C. (1988), p. 351);

As Forças de Ocupação não conseguiram destruir os valores sociais japoneses e isso foi o mais valioso legado no pós-Guerra para a recuperação da nação como um todo, em todos os aspectos. "A estrutura burocrática japonesa foi um dos aspectos da vida japonesa que o General Douglass MacArthur [comandante militar das Forças de Ocupação] falhou em reformar. Ao invés de cortar a base da pirâmide, ele simplesmente cortou o pico, com o afastamento (purge) de burocratas de setores estratégicos do governo. [...] a burocracia continuou imutável desde os dias do pré-guerra" (Editorial do Japan Times, 13/12/71); "O purge de oficiais do pós-guerra [...] ajudou a aprofundar o poder da burocracia econômica [...] deixando-a quase intacta" (Calder, K. E. (1988), pp. 150-51);

Os valores sociais baseados nos conceitos de giri, ninjô e wa permitiram que os burocratas do governo tivessem colocação garantida quando de suas aposentadorias no serviço público. Por terem passado pelo governo, por terem sido membros dessa importante elite de burocratas, esses oficiais gozavam de grande prestígio no meio empresarial levando-os a receberem inúmeros convites das empresas para assumirem importantes cargos de direção quando dos seus afastamentos dos quadros do governo. Isso permitia, por exemplo, que esses ex-burocratas, já como diretores e presidentes das empresas, tivessem acesso direto a importantes canais de informação dentro dos ministérios econômicos e de ação político-econômica do governo. Assim, podiam trazer para as empresas as informações mais precisas e o mais rapidamente possível para que assim encontrassem tempo hábil para efetuarem as mudanças e/ou adaptações necessárias para receberem investimentos e privilégios do governo, como isenções de tarifas, de taxas, incentivos a exportações, redução de tarifas de importações, empréstimos bancários subsidiados etc. Além disso, esses ex-burocratas podiam agir mais intimamente junto aos seus colegas de ministérios, uma vez que já haviam trabalhado juntos, havendo, portanto, uma fácil comunhão de interesses. Esse processo de ingresso de um ex-burocrata do governo nos quadros de direção de uma empresa ficou conhecido como amakudari ("descendente do céu");

Através de controle rigoroso e rígido, o Governo controlava o financiamento às empresas, privilegiando aquelas previamente selecionas pelo Ministério da Indústria e Comércio Internacional (MICI) e canalizava a essas empresas a quase totalidade dos recursos disponíveis procurando dinamizar a força exportadora da economia. Para minimizar conflitos com os setores e empresas não contemplados em sua política 
econômica, o governo procurava estimular federações e associações setoriais e empresariais fazendo com que a sociedade entendesse a sua orientação econômica e o seu empenho em recuperar a economia. Nesse sentido, foram criados inúmeras associações (Gyôkai) e conselhos (Shingikai) industriais como os conselhos consultivos, os conselhos de pesquisa (Shinsakai), os conselhos permanentes (Kyôgikai), os conselhos de estudo e/ou análise (Chôsakai) e os conselhos ad hoc (Kodantai); muitos conselhos ainda apresentavam subdivisões mais específicas e especiais (Iinkai);

Dentre esses conselhos, destacavam-se três que eram mais ligados à esfera econômica, a saber: o Conselho Econômico (Keizai Shingikai) -ligado à Agência de Planejamento Econômico (APE), o Conselho de Estrutura Industrial (Sangyô Kôzô Shingikai) ligado ao MICI, e o Conselho de Capital Externo (Gaishi Shingikai) - ligado ao Ministério das Finanças (MF);

Dada essa estrutura e com base nas noções de giri, ninjô e wa-notadamente esse último, o governo, através do MICI e do MF podia plenamente implantar sua política industrial, decidindo e agindo através de um processo prévio de contenção de conflitos, através, por exemplo, da obtenção de consenso, da prática do iken o matomeru. Esse processo todo era facilitado, como visto acima, dada a rede de organizações previamente criadas para tornar suave e menos conflituosa a tomada de decisões; O processo de obtenção de wa junto ao setor privado contava com a participação do governo, através do MICI e com a participação do setor privado e da sociedade civil, através da Federação das Organizações Econômicas (KEIDANREN - Keizai Dantai Rengokai), do Comitê para o Desenvolvimento Econômico do Japão (NIKKEIREN - Nihon Keieisha Dantai Rengokai) e da Câmara de Indústria e Comércio do Japão (NISSHO - Nihon Shōkō Kaigisho);

A prática do wa no setor privado compreendia a minimização de conflitos entre os setores econômicos e entre as empresas, envolvendo as seguintes etapas: a) coordenação macro-econômica; b) coordenação vertical global; c) coordenação entre os grupos industriais; d) coordenação global entre os grupos; e) coordenação global no interior do grupo; f) coordenação horizontal;

O valores sociais giri, ninjô e wa permitiram ao MICl implantar controles de ordem econômica, pois esses permitiram uma redução drástica de conflitos entre governo e empresas. Esse processo ficou conhecido como orientação administrativa (Gyôsei Shidô);

A presença da tradição: Talvez o principal fator que possibilitou a permissibilidade e que contribuiu para o amálgama entre governo e setores econômicos tenha sido a herança cultural da sociedade japonesa, uma herança sempre lembrada e convocada pelo governo no sentido de se unir forças e objetivos que colocassem os interesses da nação em primeiro lugar. Assim sendo, mesmo com a abolição forçada dos poderes do imperador no pós-guerra, a nova constituição imposta pelas Forças de Ocupação pouco fez no sentido de romper definitivamente com os valores seculares da sociedade japonesa que desde há muito tempo fora orientada a render respeito e obediência não só ao imperador mas também aos seus representantes, como os ministros de Estado, por exemplo; 
O wa e a empresa: dentro da empresa o processo de obtenção e formação de consenso sobre quais medidas e decisões a serem tomadas ocorria segundo o processo de etapas sucessivas de discussão; cada nova proposta relacionada à empresa era freqüentemente proveniente dos escalōes mais baixos, até mesmo das linhas de produção; essas propostas passavam por todos os escalões da empresa ao longo da hierarquia, sendo colhidas aprovações, reprovações ou revisões até chegar ao presidente da empresa. Uma vez aceita a proposta, havia um consenso organizacional, passando-se imediatamente a sua execução através da devida preparação (nemawashi) da empresa para incorporar a mudança, não se atribuindo menções individuais e a idéia passava a ser considerada como algo pertencente a todos;

$O$ wa e a força de trabalho: para assegurar a cooperação entre trabalhadores e empresários na formação do consenso e de uma mão-de-obra estável e sem riscos de conflitos e/ou greves, foi criado o Conselho de Reabilitação Industrial, que também garantia a participação dos trabalhadores no gerenciamento das empresas. Esse conselho permitiu a cooperação entre líderes industriais, notadamente aqueles pertencentes ao Comitê Japonês para o Desenvolvimento Econômico (Keizai Dôyûkai) e os trabalhadores; esse conselho tinha ainda a missão de implantar no Japão um capitalismo modificado;

Tendo estabelecido a autoridade gerencial e colocado nas mãos dos executivos a liderança, as condições tornavam-se propícias para exigir total produtividade por parte dos trabalhadores;

$O$ wa e o gerenciamento da empresa: Esse processo normalizou e completou o estilo japonês de gerenciamento participativo, já iniciado em períodos anteriores à guerra, o que, associado à orientação e às atitudes paternalistas da empresa levando-a a ser concebida como uma grande família, provocaram no trabalhador um sentimento de lealdade à empresa, tornando-o mais ligado a ela e ao seu desempenho. A partir de então, os trabalhadores passaram a dedicar maior esforço na obtenção de maiores índices de produtividade e de lucros para a empresa, pois grande parte de sua vida e seu próprio futuro estavam a ela relacionados e dela dependiam.

Com base em todas essas observações, concluímos que, de fato, o estudo do processo econômico japonês se torna muito mais rico se se levar em consideração a questão da herança dos valores sociais herdados do período anterior à guerra, notadamente aqueles valores compreendidos nos conceitos de giri, ninjô e wa, relatados acima e que tiveram influência e participação decisiva na formulação e implementação da política industrial do governo no pós-Guerra em todos os níveis, como: governo, setor privado, empresa e indivíduo, bem como em todas as relações envolvendo essas instituições e agentes econômicos.

\section{Bibliografia Parcial}

ABEGGLEN, James C.; RAPP, William V. (1970). "Japanese managerial behavior and "excessive competition' ". The Developing Economies. Tóquio. The Institute of Asian Economic Affairs. 4 (VIII):427-444. 
ADAMS, T. F. M.; HIROSHI, Iwao (1972). A financial history of the new Japan. Tóquio. Kodansha International Ltd. $547 \mathrm{p}$.

ALLEN, G. C. (1981). A short economic history of modern Japan. MacMillan Press. $4^{\text {a }}$ ed. 305 p.

AOKI, M. (1988). "The japanese bureacracy in economic administration: a rational regulator or pluralist agent". In SHOVEN, J. B. (ed.). Government policy towards industry in the United States and Japan. Cambridge. Cambrdige University Press. pp. 265-300.

BALASSA, Bela; NolAND, Marcus (1988). Japan in the world economy. Washington. Institute for international Economics. 290 p.

BELL, Daniel (1976). The cultural conditions of capitalism. s.l. Basic Books.

BolTHO, Andrea (1985). "Was Japan's industrial policy succesful?" Cambridge Journal of Economics. 2(9):187-201.

BrÉmOND, Janine; ChALAYE-FENET, Catherine; LOEB-PELISSIER, Michele (1989). L'économie du Japon: une menace ou un modèle? Paris. Coleção J. Brémond. $3^{\mathrm{a}}$ ed. 279 p.

BROADBRIDGE, Seymour (1966). Industrial dualism in Japan: a problem of economic growth and structural change. Chicago. Aldine Publishing. 105 p.

CALDER, Kent E. (1988). Crisis and compensation: public and political stability in Japan, 194986. Princeton. Princeton University Press.

COLE, Robert E. (1978). "The late-developer hypothesis: an evaluation of its relevance for japanese employment practices”. The Journal of Japanese Studies. Seatle. 2(4):247-263. (summer).

CRAWCOUR, Sydney (1978). "The japanese employment system", The Journal of Japanese Studies. Seatle. 2(4):225-245. (summer).

CUMmingS, William K.; NAOI, Atsushi (1974). "Social background, education, and personal advancement in a dualist employment system" In: The Developing Economies. Tóquio. The Institute of Asian Economic Affairs. 3(XII):245-273.

DoI, Takeo (1973). Amae no Kôzô. (Anatomia da Dependência). Tóquio. Kodansha. 170 p.

DORE, Ronald P. (1988). Flexible rigidities: industrial policy and structural adjustment in the japanese economy 1970-1980. London. The Athlone Press. 278 p.

(1983). "Goodwill and the spirit of market capitalism" In: ОкIмото, Daniel I.; ROHLEN, Thomas P. (1988). Inside japanese system: readings on contemporary society and political economy. Stanford University Press. pp. 90-99. Originalmente publicado em (1983) In: The British Journal of Sociology. 4(34):459-81. Routledge e Kegan Paul (publ.).

(1984). “The 'earn from Japan' boom: adpting the best". In: Speaking of Japan. Tokyo. Keizai Kôhô Center. Japan Institute for Social and Economic Affairs. 47(5):16-24.

FAURE, Guy (1987). "La politique des telecommunications: le 'dissensus' japonais". In: BERQUE, Augustin (1987). Le Japon et son Double: Logiques d'un autoportrait. Paris. Masson. 104 p. (1984). "Le rôle du miti dans l'élaboration du consensus industriel". In: BouISsou, Jean-Marie; FAURE, Guy (1984). In: Japon: le consensus: mythe et réalités. Paris. Economica. pp. 367.394.

FREEMAM, Christopher (1987). Technology policy and economic performance: lessons from Japan. London. Pinter Publishers. 155 p.

FURUKAWA, Shinji (1987). "A new industrial structure: miti's policies toward the 21 st century". In: Speaking of Japan. Tóquio. Keizai Kôhô Center. Japan Institute for Social and Economic Affairs. 73(7):1-10.

FuMIO, K. (1984). "Policy innovation at miti". Japan Echo. Tóquio. 2(11):66-69.

GiBNEY, Frank (1979). Japan; the fragile super power. Tóquio. Charles E. Tuttle Co. $2^{\mathrm{a}}$ ed. $430 \mathrm{p}$.

HARADA, Kazuaki (1984). "Vitality and resilience". In: Speaking of Japan. Tóquio. Keizai Kôhô Center. Japan Institute for Social and Economic Affair. 46(5):1-5. 
HELLMANN, Donald C. (1988). "Japanese politics and foreign policy: elitist democracy within an amercian greenhouse". In: INOGUCHI, Takashi; ОкIMOTO, Daniel I. (1988). The political economy of Japan: the changing international context. Stanford. Stanford University Press. (2):345-378.

HIDEO, Ôtake (1983). "Postwar politics: liberalism versus soicial democracy". Japan Echo. Tokyo. 2(10):43-53.

HIROSHI, Okumura (1982). "The closed nature of japanese intercorporate relations". Japan Echo. Tokyo. 3(IX):53-97. Traduzido de Masatu o umu Nihon teki keiei no heisa sei. In: Ekonomisuto. 06/07/92. pp. 34-40.

HIRSHMAN, Albert O. (1970). Exit, voice and loyalty: responses to decline inf firms, organizations and states. Harvard. Harvard University Press. $162 \mathrm{p}$.

HOLDER, J. E. (1988). "Corporate capital structure in the United States and Japan: financial intermediation and implications of financial deregulation". In: SHOVEN, J. B. (ed.). Government policy towards industry in the United States and Japan. Cambridge. Cambridge University Press. pp. 241-263.

HoRvath, Dezso; MCMillan, Charles (1980). "Industrial planning in Japan" California Management Review. 1(23):11-21 (fall).

HUNTER, Janet E. (1984). Concise Dictionary of Modern Japanese History. Tokyo. Kodansha Ltd. $347 \mathrm{p}$.

IKEMOTO, Kiyoshi (1973). "Some reflections on the Theory of dualistic economic development" Kobe University Economy Review. Kobe. (19):21-29.

IKE, Nobutaka (1972). Japanese politcs: patron client democracy. New York. Alfred A. Knopf. $2^{\mathrm{a}}$ ed. $149 \mathrm{p}$.

IMAI, Ken'ichi (1986). "Japan's industrial policy for high technology industry". In: PATRICK, H. T. (ed.). Japan's high technology industries: lessons and limitations of industrial policy. Washington. University of Washington Press. pp. 137-169.

(1990). "The legitimacy of Japan's corporate groups". Economic Eye. A Quartely Digest of Views from Japan. Tóquio. 3(11):16-21. (autumn). Originalmente publicado in Shukan Toyo Keizai. 26/05/90.

IMAI, Ken'ichi; UEKUSA, Masu (1978). "Industrial organization and economic growth in Japan" In: Tsuru, Shigeto (ed.). Growth and resources problems related to Japan. Tóquio. Asahi Evening News. pp. 91-112.

ITô, Daiichi (1968). "The bureaucracy: its attitudes and behavior". In: The Developing Economies. Tóquio. Institute of Developing Economies. 4(VI):446-467.

IVEROTH, Axel (1988). "The case against Japan: economic myth and political reality". Speaking of Japan. Tóquio. Keizai Kôhô Center. Japan Institute for Social and Economic Affairs. 94(9):1-7. (outubro).

JAPAN Culture Institute (1970). Politics and economics in contemporary Japan. Tóquio, 232 p. JOHNSON, Chalmers (1975). "Japan: who governs? an essay on official bureaucracy". In: The Journal of Japanese Studies. Seatle. 2(1):1-28.

(1982). MITI and the japanese miracle: the growth of industrial policy, 19251975. Stanford. Stanford University Press. 393 p.

(1985). "The institutional foundation of japanese industrial policy" California Management Review. 4(27):59-69. (Primeira versão apresentada na American Enterprise Institute em 01/10/84).

(1988). "Studies of japanese political economy: a crisis in theory" The Japan Foundation Newsletter. Tokyo. 3(16):1-11. (dezembro). 
HOLDEN Jr., Matthew (1966). " 'Imperialism' in bureaucracy" The American Political Science Review. Washington. The American Political Science Association. 4(LX):943-951. (dezembro)

KATSUTO, Uchihashi (1983). "Behind the scenes at miti". Japan Echo. Tokyo. 4(10):44-49.

KAWAGUCHI, Hiroshi (1967). "The 'dual structure' of finance in post-war Japan". In: The Developing Economies. Tóquio. The Institute of Asian Economic Affairs. 2(v):300-328.

(1970). “ 'Over-loan' and the investment behavior of firms". In: The Developing Economies. Tóquio. The Institute of Asian Economic Affairs. 2(v):300-328.

KôICHI, Kishimoto (1988). Politcs in modern Japan: development and organization. Tóquio. Japan Echo Inc. 3a. ed. 193 p.

KOMIYA, Ryutaro (1986). “Industrial policy's generation gap". Economic Eye: A Quartely Digesty of Views from Japan. Tóquio. 1(7):22-24. (março) Originalmente publicado in: Nihon Keizai Shimbum, 1985, pp. 18-23.

. (1990). The japanese economy: trade, industry and government. Tokyo. University of Tokyo Press. 396 p.

KoSAI, Yutaka; OGINO, Yoshitaro (1984). The contemporary japanese economy. Série Studies in the Modern Japanese Economy. MacMillan.

LANCIAUX, Bernadette (1991). "Ethnocentrism in U.S./ japanese trade policy negotiations". Journal of economic Issues. Sacramento. California State University. 2(XXV):569580.

LANGDON, Frank C. (1961). "Big business lobbying in Japan: the case of central bank reform" The American Political Science Review. Washington. The American Political Science Association. 4 (LV):527-538. (dezembro).

LOCKWOOD, William W. (1965). The state and economic enterprise in Japan: essays in the political economy of growth. Princeton. Princeton University Press. 753 p.

MIYAZAKI, Isamu (1970). "Economic planning in postwar Japan”. In: The Developing Economies. Tóquio. The Institute of Asian Economic Affairs. 4 (VIII):369-385.

(1990). The japanese economy: what make it tick. Tokyo. The Samuel Press, Inc. $1^{\mathrm{a}}$ ed. 249 p.

MIYOSHI, Masaya (1990). "Competition, cooperation, interdependence in a shrinking world, Japan reassesses its role". In: Speaking of Japan. Tóquio. Keizai Kôhô Center. Japan Institute for Social and Economic Affairs. 115(11):20-24.

Mizuno, Takeshi (1959). "Problems of small and medium industries in Japan". Kobe Economic Review. Kobe. (5):75-88.

(1971). "Development of small business organization in Japan: their characteristic features and some future prospects". Kobe University Economic Review. Kobe. (17:19-27).

MORISHIMA, Michio (1982). Why has Japan "succeeded"?: western technology and the japanese ethos. Cambridge. Cambridge University Press. 209 p.

MURAKAMI, Yasuke (1987). "The Japanese model of political economy". In: YAMAMURA, K.; YasubA, Y. (ed.) (1987). The Political Economy of Japan: The Domestic Transformation. Stanford. (1). Stanford University Press.pp. 33-90.

Muramatsu, Michio; Krauss, Ellis S. (1984). "Bureaucrats and politicians in policy-making: the case of Japan" The American Political Science Review. Washington. The American Political Science Association. 1(78):126-146. (março).

NAKAMURA, Hideichirô (1979). "Plotting a new economic course". Japan Echo. Tóquio. (VI):1120. Traduzido de Gendai Nihon Keizai. (1). In: Chikuma Shobô, 1976.

NAMIKI, Nobuyoshi (1975). “A vision of Japan's industrial structure”. In: Social structure and economic dynamics in Japan up to 1980. Institute of Economic and Social Studies for East 
Asia. Série East Asian Economy and Society. (1). Milan. Luigi Bocconi University. pp. 223-238.

NAMIKI, Nobuyoshi (1979). "Japan, inc.: reality or façade?" In: Japan Culture Institute. Politcs and economics in contemporary Japan. Tóquio. pp. 111-126.

NAOHIRO, Amaya (1981). "Harmony and the antimonopoly law". Japan Echo. Tokyo. 1 (VIII):8595. Traduzido de Wa no rinri to dokkin hô no ronri. In: Bungei Shunjû. dezembro,1980.pp. 176-193. (10):38-43.

NEALE, Walter C. (1987). "Institutions" Journal of Economic Issues. Sacramento. California State University. 3(XXI):1177-1206.

NiINO, Koujiro (1961). "The logic of excessive competition - with reference to the japanese inter-firm competition". Kobe University Economic Review. Kobe. (8):51-62.

(1968). "Industrial organization policy and economic growth in postwar Japan". Kobe University Economic Review. Kobe. (14):29-41.

(1975). "Dilemmas of anti-monopoly policy in Japan" In: Kobe University Economic Review. Tóquio. 21:1-9.

OHKAWA, K; RosovSKY, H. (1973). Japanese economic growth. Stanford. Stanford University Press.

PHP INSTITUTE, Inc. (ed.) (1989). "What's what in Japan's diet, government, and public agencies" Tóquio. The Japan Times. $166 \mathrm{p}$.

RICHARDSON, Bradley; UEDA, Taizo (eds.) (1981). Business and society in Japan: fundamentals for businessmen. New York. East Asian Studies, Ohio State University. Praeger. 334 p.

RAPPING, Leonard A. (1984). "Bureaucracy, the corporation, and economic policy". In: Journal of Post Keynesian Economies. New York. M. E. Sharpe, Inc. 3(VI):337-353.

ROTBERG, Eugene H. (1986). "Consultation, competition, and control" In: Speaking of Japan. Tóquio. Keizai Kôhô Center. Japan Institute for Social and Economic Affairs. 61(6):14-20.

SABA, Shoichi (1986). "Vision, consensus, and competition: industrial policy in Japan". Speaking of Japan. Tokyo. Keizai Kôhô Center. Japan Institute for Social and Economic Affairs. 77(8):10-16. (maio)

SHIMADA, Haruo (1982). "Perceptions and the reality of japanese industrial relations: role in Japan's postwar industrial success". In: Keio Economic Studies. Tóquio. The Keio Economic Society. Keio University. 2(XIX):1-21.

SUGIMORI, Kôji (1968). "The social background of political leadership in Japan" In: The Developing Economies. Tokyo. The Institute of Asian Economic Affairs. 4 (VI):487-509.

YamamuRA, Kozo (1979). "Behind the 'made in Japan label'" In: Japan Culture Institute. Politics and Economics in Contemporary Japan. Tóquio. pp. 127-142.

WARD, R. R. (1956). "The origins of the present japanese constitution". The American Political Science Review. Washington. The American Political Science Association. 4 (L):981-1010. WOLFEREN, Karel van (1989). The enigma of japanese power: people and politics in a stateless nation. London. MacMillan. $496 \mathrm{p}$.

Zimmerman, Mark A. (1985). Dealing with the japanese. London. Unwin Paperbacks. 316 p.

Elvino José Barbosa

Centro de Estudos Japoneses da USP 